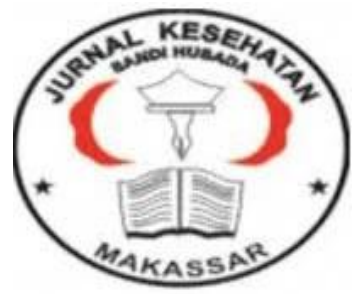

\author{
Jurnal Ilmiah Kesehatan Sandi Husada \\ hhttps://akper-sandikarsa.e-journal.id/JIKSH \\ Volume 9, Nomor 2, Desember 2020, pp 947-952 \\ p-ISSN: 2354-6093 dan e-ISSN: 2654-4563 \\ DOI: $10.35816 /$ jiskh.v10i2.444
}

\title{
Penerapan Aspek Spiritualitas dengan Pemenuhan Kebutuhan Spiritual Pada Pasien
}

Application of Aspects of Spirituality by Fulfilling the Spiritual Needs of the Patient

\section{Achmad Amiruddin ${ }^{1}$, Murniati Murniati ${ }^{2}$}

12 Akademi Farmasi, Sandi Karsa

Artikel info

Artikel history:

Received; Agustus 2020

Revised: September 2020

Accepted; Oktober 2020

\begin{abstract}
.
Background; nurses believe that humans are bio-psycho-socio-cultural and spiritual beings who are intact and respond to changes that occur, among others, due to health problems and irregularities in fulfilling needs. Aim; know the relationship between the application of spiritual aspects of nurses with the fulfillment of spiritual needs in inpatients at Barombong Health Center. Method; Descriptive analytic research design using the Crosssectional design method to take measurements or observations at the same time with purposive sampling technique sampling. Data obtained through a questionnaire that was processed using the SPSS computer program. Univariate and bivariate data analysis and description. Result; The statistical test obtained the value of $\rho=0.034<\alpha=0.05$, there is a relationship between the application of the spirituality aspects of nurses and the fulfillment of the spiritual needs of patients. Conclusion; There is a relationship between the application of the spirituality aspects of nurses with the fulfillment of spiritual needs for inpatients. There needs to be a strategy in improving health services, especially in applying the spiritual needs of the patient.
\end{abstract}

\begin{abstract}
Abstrak
Latar belakang; perawat meyakini manusia sebagai makhluk bio-psikososio-kultural dan spiritual yang utuh berespons terhadap suatu perubahan yang terjadi antara lain karena gangguan kesehatan dan penyimpangan pemenuhan kebutuhan. Tujuan; mengetahui hubungan penerapan aspek spiritualitas perawat dengan pemenuhan kebutuhan spiritual pada pasien rawat inap di Puskemas Barombong. Metode; Desain penelitian analitik deskriptif dengan menggunakan metode desain Cross Sectional melakukan pengukuran atau pengamatan pada saat bersamaan dengan teknik pengambilan sampel secara Purposive Sampling. Data diperoleh melalui kuesioner yang diolah dengan menggunakan program komputer SPSS. Analisis data univariate dan bivariat dan deskripsi. Hasil; uji statistik diperoleh nilai $\rho=0.034<\alpha=0.05$, terdapat hubungan penerapan aspek spiritualitas perawat dengan pemenuhan kebutuhan spiritualitas pasien. Kesimpulan; terdapat hubungan penerapan aspek spiritualitas perawat dengan pemenuhan kebutuhan spititualitas terhadap pasien yang dirawat inap. Perlu ada strategi dalam meningkatkan pelayanan kesehatan khususnya dalam penerapan aspeks kebutuhan spiritual pasien.
\end{abstract}


Keywords:

Aspek spiritualitas;

Kebutuhan spiritual;
Coresponden author:

Email: achmadamiruddin74@gmail.com

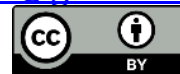

artikel dengan akses terbuka dibawah lisensi CC BY -4.0

\section{Pendahuluan}

Perawat meyakini manusia sebagai makhluk bio-psiko-sosio-kultural dan spiritual yang utuh berespons terhadap suatu perubahan yang terjadi antara lain karena gangguan kesehatan dan penyimpangan pemenuhan kebutuhan. Untuk dapat memenuhi kebutuhan secarra holistik dan unik diperlukan pendekatan yang komprehensif dan bersifat individual bagi tiap sistem klien. Perawat sebagai tenaga kesehatan yang professional mempunyai kesempatan yang paling besar untuk memberikan pelayanan kesehatan khususnya pelayanan/asuhan keperawatan yang komprehensif dengan membantu klien memenuhi kebutuhan dasar yang holistik. Perawat memandang klien sebagai makhluk bio-psikososio-kultural dan spiritual yang berespon secara holistik dan unik terhadap perubahan kesehatan atau pada keadaan krisis (Hamid \& Hamid, 2000).

Spiritualitas adalah keyakinan dalam hubungannya dengan yang Maha Kuasa. Sedangkan kebutuhan spiritual adalah kebutuhan untuk mempertahankan atau mengembalikan keyakinan dan memenuhi kewajiban agama, serta kebutuhan untuk mendapatkan maaf atau pengampunan. Kebutuhan spiritual merupakan kebutuhan dasar yang dibutuhkan oleh setiap manusia. Dalam pelayanan kesehatan, perawat sebagai petugas kesehatan harus memiliki peran utama dalam memenuhi kebutuhan spiritual. Perawat dituntut mampu memberikan pemenuhan yang lebih pada saat pasien akan dioperasi, pasien kritis atau menjelang ajal. Dengan demikian, terdapat keterkaitan antara keyakinan dengan pelayanan kesehatan dimana kebutuhan dasar manusia yang diberikan melalui pelayanan kesehatan tidak hanya berupa aspek biologis, tetapi juga aspek spiritual. Aspek spiritual dapat membantu membangkitkan semangat pasien dalam proses penyembuhan(Asmadi, 2018).

Ketika penyakit, kehilangan atau nyeri menyerang seseorang, kekuatan spiritual dapat membantu seseorang kearah penyembuhan atau pada perkembangan kebutuhan dan perhatian spiritual. Selama penyakit atau kehilangan, misalnya saja, individu sering menjadi kurang mampu untuk merawat diri mereka dan lebih bergantung pada orang lain untuk perawatan dan dukungan. Distres spiritual dapat berkembang sejalan dengan seseorang mencari makna tentang apa yang sedang terjadi, yang mungkin dapat mengakibatkan seseorang merasa sendiri dan terisolasi dari orang lain. Individu mungkin mempertanyakan nilai spiritual mereka, mengajukan pertanyaan tentang jalan hidup seluruhnya, tujuan hidup dan sumber dari makna hidup (Potter, 2010).

\section{Metode}

Jenis penelitian yang digunakan dengan metode deskriptif analitik dengan pendekatan cross sectional yaitu survey analitik. Dilaksanakan pada bulan Juni - September 2020. Jumlah sampel 30 orang yang memenuhi kreteria inklusi. Jenis data primer dan skunder yang diolah dengan; editing, coding, skoring, tabulasi data, analisis data univariat dan bivariat. 


\section{Hasil Dan Pembahasan}

Tabel 1. Distribusi Frekuensi Responden Berdasarkan Umur

\begin{tabular}{ccc}
\hline \hline Umur (Tahun) & Frekuensi (f) & Persentase (\%) \\
\hline $16-26$ & 5 & 16.67 \\
$27-37$ & 4 & 13.32 \\
$38-48$ & 5 & 16.67 \\
$49-59$ & 6 & 20 \\
$60-70$ & 5 & 16.67 \\
$71-81$ & 5 & 16.67 \\
\hline Jumlah (n) & $\mathbf{3 0}$ & $\mathbf{1 0 0}$ \\
\hline \hline
\end{tabular}

Sumber: Data primer 2020

Dari hasil penelitian yang telah dilaksanakan diperoleh data bahwa dari 30 responden terdapat rentang umur 16 - 26 tahun sebanyak 5 (16.67\%) responden, rentang umur 27 37 tahun sebanyak 4 (13.33\%) responden, rentang umur 38 - 48 tahun sebanyak 5 (16.67\%) responden, rentang umur 49 - 59 tahun sebanyak 6 (20\%) responden, rentang umur 60 - 70 tahun sebanyak $5(16.67 \%)$ responden, dan rentang umur 71 - 81 sebanyak $5(16.67 \%)$.

Tabel 2. Distribusi Frekuensi Responden Berdasarkan Jenis Kelamin

\begin{tabular}{ccc}
\hline \hline Jenis Kelamin & Frekuensi (f) & Persentase (\%) \\
\hline Laki-laki & 15 & 50 \\
Perempuan & 15 & 50 \\
\hline Jumlah (n) & $\mathbf{3 0}$ & $\mathbf{1 0 0}$ \\
\hline \hline
\end{tabular}

Sumber: Data primer 2020

Tabel 3 Distribusi Frekuensi Responden Berdasarkan Tingkat Pendidikan

\begin{tabular}{ccc}
\hline \hline Pekerjaan & Frekuensi (f) & Persentase (\%) \\
\hline SD & 17 & 56.7 \\
SMP & 5 & 16.7 \\
SMA & 4 & 13.3 \\
D3 & 3 & 10 \\
S1 & 1 & 3.3 \\
\hline Jumlah (n) & $\mathbf{3 0}$ & 100 \\
\hline \hline
\end{tabular}

Sumber: Data primer 2020

Tabel 5 Distribusi Frekuensi Responden Berdasarkan Penerapan Aspek Spiritualitas Perawat

\begin{tabular}{ccc}
\hline \hline $\begin{array}{c}\text { Penerapan Aspek } \\
\text { Spiritualitas Perawat }\end{array}$ & Frekuensi (f) & Persentase (\%) \\
\hline Baik & 24 & 80 \\
Kurang & 6 & 20 \\
\hline Jumlah (n) & $\mathbf{3 0}$ & $\mathbf{1 0 0}$ \\
\hline \hline
\end{tabular}

Sumber: Data primer 2020

Tabel 6 Distribusi Frekuensi Responden Berdasarkan Pemenuhan Kebutuhan Spiritual Pasien

\begin{tabular}{ccc}
\hline \hline Spiritual Pasien & Frekuensi (f) & Persentase (\%) \\
\hline Terpenuhi & 28 & 93.3 \\
Tidak Terpenuhi & 2 & 6.7 \\
\hline Jumlah (n) & $\mathbf{3 0}$ & $\mathbf{1 0 0}$ \\
\hline \hline
\end{tabular}

Sumber: Data primer 2020 
Tabel 7. Analisis Hubungan Penerapan Aspek Spiritualitas Perawat dengan Pemenuhan Spiritual Pasien

\begin{tabular}{|c|c|c|c|c|c|c|}
\hline \multirow{3}{*}{$\begin{array}{c}\text { Penerapan Aspek } \\
\text { Spiritualitas Perawat }\end{array}$} & \multicolumn{4}{|c|}{$\begin{array}{l}\text { Pemenuhan Kebutuhan } \\
\text { Spiritual Pasien }\end{array}$} & \multirow{2}{*}{\multicolumn{2}{|c|}{ Jumlah }} \\
\hline & \multicolumn{2}{|c|}{ Cukup } & \multicolumn{2}{|c|}{ Kurang } & & \\
\hline & f & $\%$ & $f$ & $\%$ & $\mathbf{n}$ & $\%$ \\
\hline Baik & 24 & 80 & 0 & 0 & 24 & 80 \\
\hline Kurang & 4 & 13.3 & 2 & 6.7 & 6 & 20 \\
\hline Jumlah (n) & 28 & 93.3 & 2 & 6.7 & 30 & 100 \\
\hline
\end{tabular}

Sumber: Data primer 2020

Hasil Analisis hubungan antara penerapan aspek spiritualitas perawat dengan pemenuhan kebutuhan spiritual pasien diperoleh bahwa terdapat 24 (80\%) responden yang pemenuhan kebutuhan spiritual pasien cukup dengan penerapan aspek spiritualitas perawat baik, tetapi terdapat $0(0 \%)$ responden yang pemenuhan kebutuhan spiritual pasien kurang dengan penerapan aspek spiritualitas perawat baik, sedangkan terdapat 4 (13.3\%) responden yang pemenuhan kebutuhan spiritual pasien cukup dengan penerapan aspek spiritualitas perawat kurang serta terdapat 2 (6.7\%) responden yang pemenuhan kebutuhan spiritual pasien kurang dengan penerapan aspek spiritualitas perawat kurang.

Hasil analisis menunjukan bahwa terdapat hubungan antara penerapan aspek spiritualitas perawat dengan pemenuhan kebutuhan spititual pasien diperoleh bahwa terdapat 24 (80\%) responden yang pemenuhan kebutuhan spiritual pasien cukup dengan penerapan aspek spiritualitas perawat baik. Menurut teori yang dikemukakan oleh (Taylor, 1997), nilai dari keyakinan agama tidak dapat dengan mudah dievaluasi. Walaupun demikian pengaruh keyakinan tersebut dapat diamati oleh tenaga kesehatan dengan mengetahui bahwa individu cenderung dapat menahan distress fisik yang luar biasa karena mempunyai keyakinan yang kuat. Klien akan mengikuti semua proses penyembuhan yang memerlukan upaya luar biasa, karena keyakinan bahwa semua upaya tersebut akan berhasil. Sejalan dengan teori yang dikemukakan diatas peneliti berpendapat hal ini terjadi karena perawat memiliki peran utama untuk memberikan pelayanan dalam memenuhi kebutuhan spiritual pasien berupa pelayanan kesehatan khususnya pelayanan/asuhan kepawatan yang komprehensif dengan membantu klien memenuhi kebutuhan dasar holistik, tetapi terdapat $0(0 \%)$ responden yang pemenuhan kebutuhan spiritual pasien kurang dengan penerapan aspek spiritualitas perawat baik. Menurut hasil penelitian Arini(Arini et al., 2015) bahwa persespsi perawat terhadap nilai spiritual berkontribusi terhadap perkembangan kemampuan professional untuk memberikan asuhan spiritual. (Sidabutar, 2016) berpendapat bahwa terdapat hubungan penerapan aspek spiritualitas oleh perawat dengan pemenuhan kebutuhan spiritual pada pasien. Oleh karena itu, perlunya pelatihan pendidikan penerapan aspek spiritual kepada perawat untuk dapat melakukan pemenuhan kebutuhan spiritual pasien.

Pemenuhan kebutuhan spiritual menjadi aspek penting dalam proses kesembuhan klien. Aspek tersebut merupakan tugas perawat untuk memenuhi dengan melihat kebutuhan spiritual yang tepat bagi klien. Perawat dituntut mampu tidak mengenyampingkan kebutuhan spiritual dan selalu berkoordinasi dengan tim kesehatan lainnya dalam diskusi pertemuan rumah sakit atau manajemen rumah sakit (Tricahyono, 2015). Hasil penelitian Bawono (Bawono, 2011) menunjukkan bahwa aspek spiritualitas-religiusitas merupakan aspek sekunder dalam pengambilan keputusan memilih RS Islam. Sehingga aspek ini berperan penting bagi organisasi kesehatan untuk bersaing dalam pelayanan kesehatan. 
Menurut hasil penelitian (Wibawa \& Nurhidayati, 2020) menyatakan bahwa ada pengaruh pada pasien yang diberikan pendekatan spiritual, minimal pada tingkat pengetahuan dan pemahaman pasien tentang hubungannya dengan Tuhan, diri sendiri dan orang lain yang terkait dengan perilaku maladaptifnya. Hasil penelitian (Husna \& Elvania, 2020) tidak ada perbedaan pengetahuan perawat dalam penanganan masalah psikologis dan spiritual. Namun ada perbedaan sikap perawat dalam penanganan masalah psikologis dan spiritual. Berdasarkan analisa akan kebutuhan spiritualitas tersebut semua responden mengatakan sangat membutuhkan aspek kebutuhan akan beragama(Fitroti, 2018).

Menurut (Wahyunengsih, 2015) menunjukkan bahwa kebutuhan spiritual pasien yang dalam pelayanan keperawatan dalam kriteria tinggi, namun dalam pemenuhan kebutuhan spiritualnya tergolong terpenuhi, meskipun dominan hanya dipenuhi dari keluarga namun tidak dalam pelayanan keperawatan. Bahwa perawat menyadari bahwa memperhatikan kebutuhan spiritual pasien meningkatkan kualitas asuhan keperawatan secara keseluruhan. Namun, terlepas dari semua perhatian yang diberikan pada dimensi spiritual, mayoritas perawat masih merasa bahwa mereka memerlukan lebih banyak bimbingan dan dukungan dari badan pengatur untuk memungkinkan mereka mendukung dan secara efektif memenuhi kebutuhan spiritual pasien mereka(McSherry \& Jamieson, 2011). Dalam tahap implementasi didasarkan pada rencana yang telah disusun bersama klien dan keluarga. Dalam mengevaluasi proses keperawatan pada klien selalu mengacu pada tujuan pemenuhan kebutuhan klien(Suprapto, 2020).

Bahwa ada kesenjangan yang signifikan dalam hal memenuhi kebutuhan spiritual pasien dalam praktik keperawatan. Diusulkan agar lebih banyak penekanan ditempatkan pada pengintegrasian konten spiritualitas ke dalam program pendidikan untuk memungkinkan pengiriman klinis yang lebih efektif (Zakaria Kiaei et al., 2015). Definisi komprehensif dari konsep perawatan spiritual. Bahwa dapat memfasilitasi pengembangan lebih lanjut dari pengetahuan dan praktik keperawatan dalam asuhan spiritual dan memfasilitasi koreksi kesalahpahaman umum tentang penyediaan asuhan spiritual(Ramezani et al., 2014). Berdasarkan hasil penelitian bahwa sebagian besar kebutuhan spiritual pasien terpenuhi dibandingkan dengan kebutuhan spiritual pasien yang kurang terpenuhi.

\section{Simpulan Dan Saran}

Bahwa terdapat hubungan penerapan aspek spiritualitas perawat dengan pemenuhan kebutuhan spititualitas terhadap pasien yang dirawat inap. Perlu ada strategi dalam meningkatkan pelayanan kesehatan khususnya dalam penerapan aspeks kebutuhan spiritual pasien. Pemenuhan kebutuhan spiritual menjadi aspek penting dalam proses kesembuhan klien. Aspek tersebut merupakan tugas perawat untuk memenuhi dengan melihat kebutuhan spiritual yang tepat bagi klien.

\section{Daftar Rujukan}

Arini, H. N., Susilowati, I., \& Mulyono, W. A. (2015). Hubungan Spiritualitas Perawat Dan Kompetensi Asuhan Spiritual. Jurnal Keperawatan Soedirman, 10(2), 130-140.

Asmadi, A. (2018). Teknik prosedural keperawatan: konsep dan aplikasi kebutuhan dasar klien (19). Salemba Medika.

Bawono, A. (2011). Penerapan Aspek Spiritualitas-Religiusitas dalam Keputusan Berobat di Rumah Sakit Islam. INFERENSI: Jurnal Penelitian Sosial Keagamaan, 5(1), 1939.

Fitroti, Z. A. K. U. (2018). Faktor-Faktor Prediksi Spiritualitas Pada Pasien Kemoterapi Wanita Dengan Kanker Rsud Prof Dr Margono Soekarjo Purwokerto. UNIVERSITAS MUHAMMADIYAH PURWOKERTO. 
Hamid, A. Y., \& Hamid, S. (2000). Aspek spiritual dalam keperawatan. Widya Medika: Jakarta.

Husna, C., \& Elvania, J. (2020). Pengetahuan Dan Sikap Perawat Terhadap Penanganan Masalah Psikologis Dan Spiritual Pada Pasien Pasca Bencana: A Comparative Study. Jurnal Perawat Indonesia, 4(2), 19-28.

McSherry, W., \& Jamieson, S. (2011). An online survey of nurses' perceptions of spirituality and spiritual care. Journal of Clinical Nursing, 20(11-12), 1757-1767. https://doi.org/10.1111/j.1365-2702.2010.03547.x

Potter, P. A. (2010). Fundamental keperawatan. Elsevier.

Ramezani, M., Ahmadi, F., Mohammadi, E., \& Kazemnejad, A. (2014). Spiritual care in nursing: a concept analysis. International Nursing Review, 61(2), 211-219. https://doi.org/10.1111/inr.12099

Sidabutar, R. R. (2016). Hubungan Penerapan Aspek Spiritualitas Oleh Perawat Dengan Pemenuhan Kebutuhan Spiritual Pada Pasien Rawat Inap Di Rs. Islam Malahayati Medan. JURNAL KEPERAWATAN FLORA, 9(1), 9-20.

Suprapto, S. (2020). Penerapan Asuhan Keperawatan Pada Gangguan Sistem Pencernaan "Gastritis." Jurnal Ilmiah Kesehatan Sandi Husada, 11 (1 SE-Articles). https://doi.org/10.35816/jiskh.v11i1.211

Taylor, C. (1997). Lilis. C., Lemone, P.,. Fundamentals of Nursing: The Art and Science of Nursing Care.

Tricahyono, A. R. (2015). Motivasi Perawat dalam Pemenuhan Kebutuhan Spiritual Pada Klien di Ruang Rawat Inap Rumah Sakit Daerah Balung.

Wahyunengsih, S. (2015). Kondisi Spiritual Pasien dalam Pelayanan Keperawatan di Ruang Rawat Inap RSUD Haji Makassar. Universitas Islam Negeri Alauddin Makassar.

Wibawa, Z., \& Nurhidayati, L. (2020). Implementation Of Inovation Meeting Spiritual Needs For Soul Disorders With Spiritual Care Method In Rsj Grhasia Jogyakarta. JURNAL KEPERAWATAN AKPER YKY YOGYAKARTA, 12(1), 59-64.

Zakaria Kiaei, M., Salehi, A., Moosazadeh Nasrabadi, A., Whitehead, D., Azmal, M., Kalhor, R., \& Shah Bahrami, E. (2015). Spirituality and spiritual care in Iran: nurses' perceptions and barriers. International Nursing Review, 62(4), 584-592. https://doi.org/10.1111/inr.12222 